\title{
Technical assistance for implementing best practices in the Asia and Near East region
}

\author{
M.E. Khan \\ Population Council \\ Sohini Roychowdhury \\ Population Council \\ Mary Philip Sebastian \\ Population Council \\ Sitanshu Sekhar Kar \\ Population Council \\ Anurag Mishra \\ Population Council
}

See next page for additional authors

Follow this and additional works at: https://knowledgecommons.popcouncil.org/departments_sbsr-rh

Part of the Community-Based Research Commons, International Public Health Commons, Maternal and Child Health Commons, Obstetrics and Gynecology Commons, and the Women's Health Commons How does access to this work benefit you? Let us know!

\section{Recommended Citation}

Khan, M.E., Sohini Roychowdhury, Mary Philip Sebastian, Sitanshu Sekhar Kar, Anurag Mishra, Vivek Sharma, G. Narayana, Bhawana Sharma, Nahla G. Abdel-Tawab, and Ahmed Afifi. 2008. "Technical assistance for implementing best practices in the Asia and Near East region," FRONTIERS Final Report. Washington, DC: Population Council. 


\section{Authors}

M.E. Khan, Sohini Roychowdhury, Mary Philip Sebastian, Sitanshu Sekhar Kar, Anurag Mishra, Vivek Sharma, G. Narayana, Bhawana Sharma, Nahla G. Abdel-Tawab, and Ahmed Afifi 


\title{
Technical Assistance for Implementing Best Practices in the Asia and Near East Region
}

\author{
Frontiers in Reproductive Health, Population Council, India \\ M.E. Khan \\ Sohini Roychowdhury \\ Mary Philip Sebastian \\ Sitanshu Sekhar Kar \\ Anurag Mishra \\ Vivek Sharma \\ Constella Futures Group, India \\ G. Narayana \\ Bhawana Sharma \\ Frontiers in Reproductive Health, Population Council, Egypt \\ Nahla Abdel Tawab \\ Ahmed Afifi
}

September 2008

This study was made possible by the generous support of the American people through the United States Agency for International Development (USAID) under the terms of Cooperative Agreement Number HRN-A-00-98-00012-00, In-House Project 5802.53113 and In-House Project 5802/5806 53113/53118. The contents are the responsibility of the FRONTIERS Program and do not necessarily reflect the views of USAID or the United States Government. 


\section{EXECUTIVE SUMMARY}

The Asia and Near East (ANE) Bureau of the United States Agency for International Development (USAID) is eager to promote utilization of best practices by country missions and other cooperating agencies (CAs) in the region. To encourage this, the Population Council's Frontiers in Reproductive Health (FRONTIERS) program offered technical assistance to any ANE country mission interested in funding adaptation of USAID's "best practices" in family planning or reproductive health; the ANE Bureau provided funding for the costs of FRONTIERS technical assistance.

The USAID Mission in India selected two best practices: introducing the systematic screening instrument (SSI); and strengthening provision of emergency contraceptive pills (ECP). Both activities were implemented in the state of Uttarakhand. The USAID Mission in Egypt requested technical assistance from FRONTIERS to build national capacity for the correct use of the Lactational Amenorrhea Method (LAM); in addition, the Egypt Mission provided additional funds to expand the scope of this support to include building capacity at the national level for providing postpartum and post abortion family planning (PP PA FP) counseling.

\section{Implementing SSI and Strengthening ECP Services in Uttarakhand, India}

Several activities were carried out, including training of service providers through a cascading three-tier approach. The project began with a state-level orientation meeting for all senior program officers, which also helped in subsequent planning and monitoring of the program. Three to four Master Trainers with some training experience were trained from each of the 13 districts; altogether about 60 Master Trainers were trained in two batches. The Master Trainers in turn trained 250 primary health center doctors, who, in turn, have trained 1,620 community level workers. To improve compliance for screening, the MCH and immunization clinic registers were modified and six probing questions added so that screening became a routine process.

For the ECP training, pre and post training questionnaires were administered and other supervision and monitoring checklists were utilized to assess the quality of training provided by the trainers. FRONTIERS staff participated in the entire TOT in the 13 districts. In each district, doctors were oriented on how to supervise compliance by the providers in screening and provided checklists which the supervisors (LHVs) could use during their field visits.

FRONTIERS also provided all training materials on ECP, including posters, counseling aids for ANM/LHV (2,200 flip charts) and 300,000 ECP brochures. There was a significant increase in knowledge about ECP and its provision among providers.

\section{Building national capacity of the training institutions to promote LAM as postpartum contraception in Egypt}

Several activities were completed in Egypt under this project that included: (1) a diagnostic study to understand common practices and misconceptions among women and health care providers related to the use of breastfeeding as a method of contraception (2) holding a consensus building meeting to reach agreement on messages and activities that would enhance effective use of LAM in Egypt, (3) revising and updating national guidelines for use of LAM, (4) updating clinical guidelines for postpartum / postabortion family planning in hospital settings; (5) updating PP PA FP training curriculum for physicians and nurses on the Ob/Gyn ward, (6) training of 50 master trainers from five medical schools and five health directorates, (7) updating breastfeeding flier 
to include information on correct use of LAM and developing a Frequently Asked Question (FAQ) sheet to assist providers in counseling clients about breastfeeding and use of LAM; and (8) monitoring of PP PA FP training course that was delivered by RCT to a total of 246 physicians and nurses 50 MOHP hospitals. These activities will help the Ministry of Health and Population in developing a national postpartum postabortion family planning program and in reducing unplanned and unwanted pregnancies in Egypt. 


\section{TABLE OF CONTENTS}

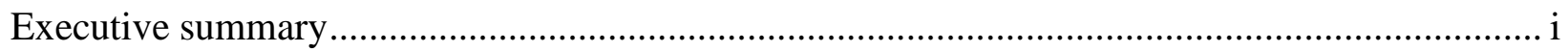

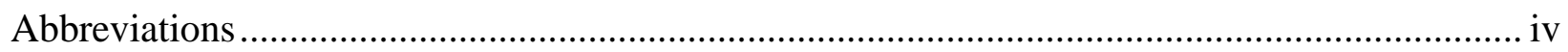

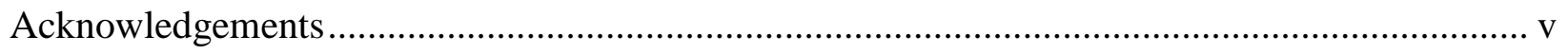

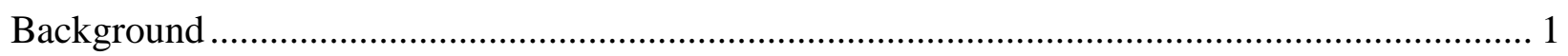

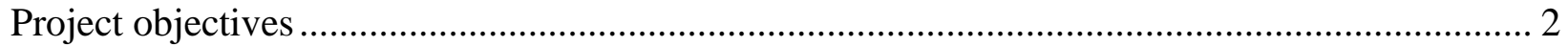

Introducing the systematic screening procedure and strengthening Emergency Contraceptive

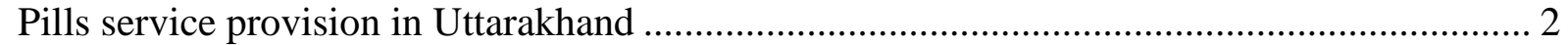

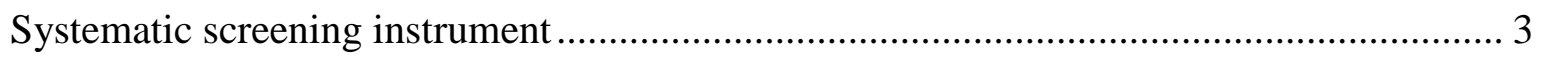

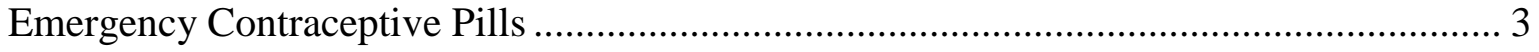

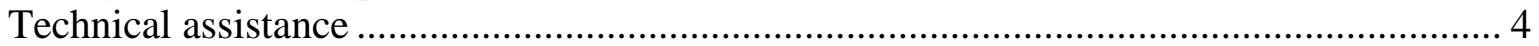

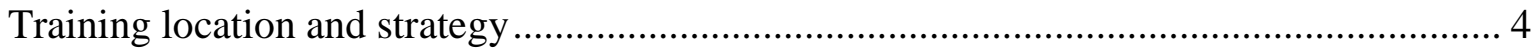

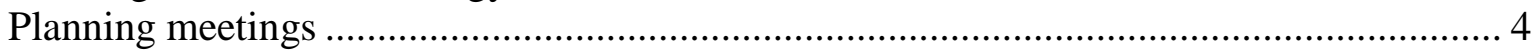

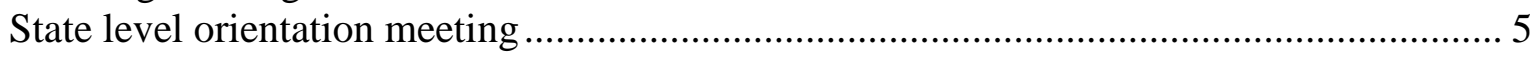

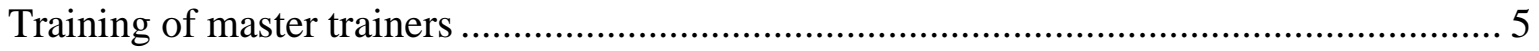

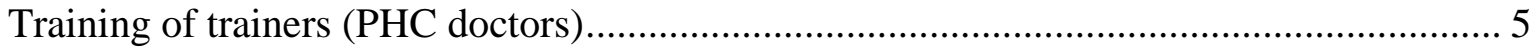

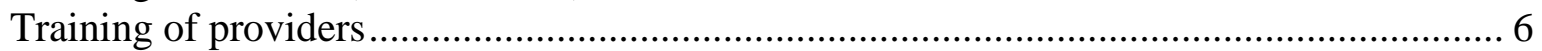

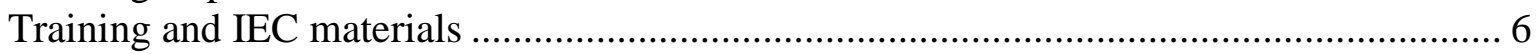

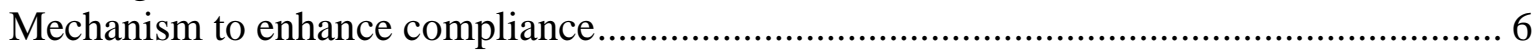

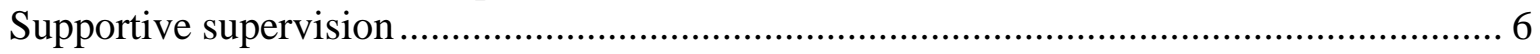

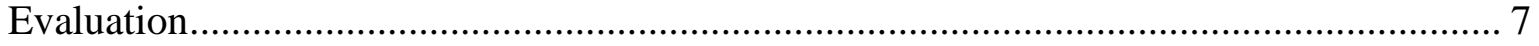

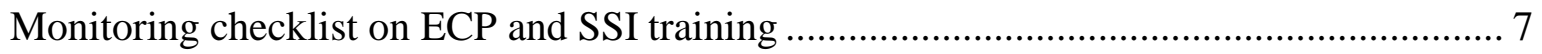

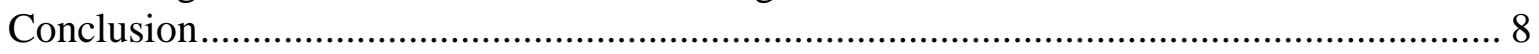

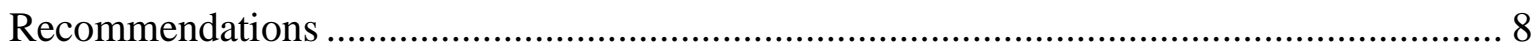

Technical assistance for Building the capacity of national training institutions to promote LAM

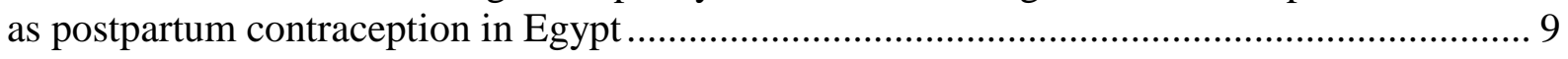

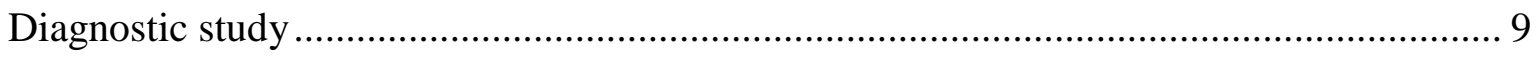

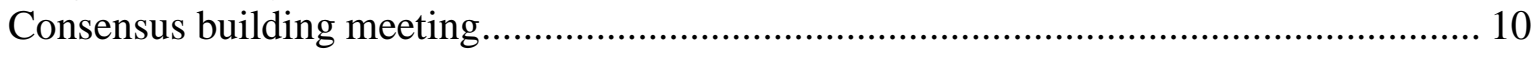

Guidelines for use of LAM ................................................................................. 11

Guidelines for postpartum and postabortion family planning ...................................... 11

Updating the postpartum / postabortion care training curriculum for hospital providers ... 11

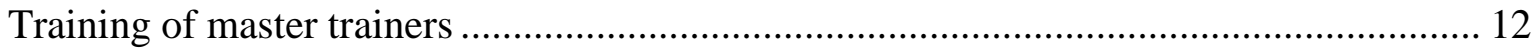

IEC materials on LAM for providers and clients ........................................................ 12

Monitoring of PP/PA FP training course delivered by RCT ....................................... 12

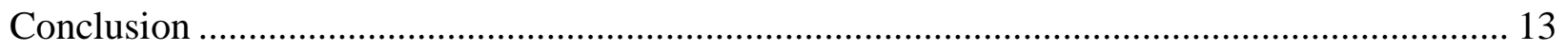

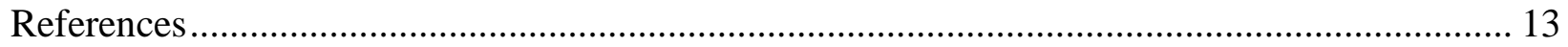

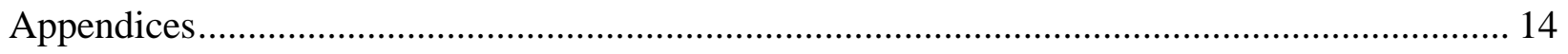

Appendix 1: IEC Materials on ECP ...................................................................... 14

Appendix 2: Revised LAM service delivery guidelines ......................................... 15

Appendix 3: Case studies on use of LAM........................................................... 18

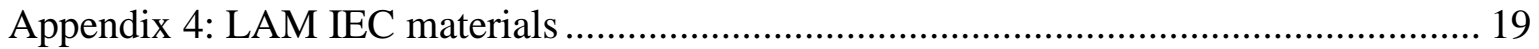

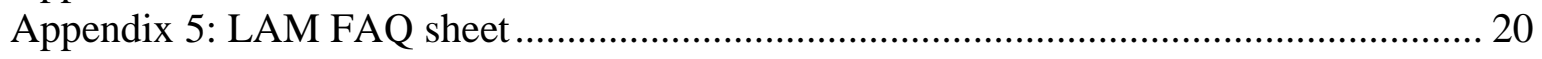




\begin{tabular}{|c|c|}
\hline \multicolumn{2}{|c|}{ ABBREVIATIONS } \\
\hline ANE & Asia and Near East \\
\hline ANM & Auxiliary Nurse Midwife \\
\hline $\mathrm{CA}$ & Co-operating Agency \\
\hline $\mathrm{CHC}$ & Community Health Center \\
\hline $\mathrm{CHL}$ & Communication for Healthy Living Project \\
\hline $\mathrm{CMO}$ & Chief Medical Officer \\
\hline DPM & District Program Manager \\
\hline ECP & Emergency Contraceptive Pills \\
\hline FAQ & Frequently Asked Questions \\
\hline FGD & Focus Group Discussion \\
\hline GOU & Government of Uttarakhand \\
\hline IEC & Information Education and Communication \\
\hline LAM & Lactational Amenorrhea Method \\
\hline LHV & Lady Health Visitor \\
\hline $\mathrm{MCH}$ & Maternal and Child Health \\
\hline MO & Medical Officer \\
\hline MOHFW & Ministry of Health and Family Welfare \\
\hline MOHP & Ministry of Health and Population \\
\hline MOIC & Medical Officer In-Charge \\
\hline NFHS & National Family Health Survey \\
\hline NRHM & National Rural Health Mission \\
\hline $\mathrm{OB} / \mathrm{GYN}$ & Obstetrics and Gynecology \\
\hline PA & Postabortion \\
\hline PHC & Primary Health Centre \\
\hline PP & Postpartum \\
\hline PNC & Postnatal Care \\
\hline $\mathrm{RCH}$ & Reproductive and Child Health \\
\hline RT & Regional Center for Training on Family Planning and Reproductive Health \\
\hline RH & Reproductive Health \\
\hline SMC & Surat Municipal Corporation \\
\hline SSI & Systematic Screening Instrument \\
\hline TA & Technical Assistance \\
\hline UNICEF & United Nations Children's Fund \\
\hline USAID & United States Agency for International Development \\
\hline VMC & Vadodara Municipal Corporation \\
\hline WHO & World Health Organization \\
\hline
\end{tabular}




\section{ACKNOWLEDGEMENTS}

This project has received sustained support from its collaborators and donors, both in India and Egypt. In India, the project was a collaborative effort of the FRONTIERS Program of Population Council, Constella Futures Group and the Directorate of Health and Family Welfare, Government of Uttarakhand. In carrying out this study in Uttarakhand many people have contributed in different ways. First of all we extend our special thanks to Ms. Manish Panwar, Principal Secretary, Health and Family Welfare, Government of Uttarakhand for her immense interest, commitment and continued support throughout this project. Our sincere gratitude to the Dr. P.L. Joshi, Director General, Directorate of Health \& Family Welfare, Government of Uttarakhand for her active participation in the project. We would also like to thank Dr. Anil Sharma, Additional Director (National Programme), Government of Uttarakhand for his active involvement and support. We are also thankful to Dr. B.C. Pathak, Senior Technical Advisor, HRC, Government of Uttarakhand for taking keen interest and implementing this project. Last but not the least, we are extremely grateful to all the Master Trainers, ANMs, LHVs/ supervisors, male workers and Anganwadi workers whose untiring efforts has made this project successful.

In Egypt, we wish to thank all those who contributed to the completion of this project to enhance the delivery of postpartum/ postabortion family planning services in Egypt. The Ministry of Health and Population under the leadership of H.E. Dr. Hatem El-Gabaly, Minister of Health and Population has strongly supported this project and has shown keen interest in integrating family planning into postpartum/postabortion care services. Our partners at TAKAMOL/ Pathfinder Project, Regional Center for Training and Communication for Healthy Living have provided tremendous support in the development of service delivery guidelines, training materials and IEC materials for this project. The comments and suggestions we received from our distinguished reviewers have been invaluable in enhancing the quality of our products.

Last but not least, we are grateful to ANE Bureau, USAID Washington and USAID Missions in India and Egypt for funding this activity. Special thanks go to Ms. Monique Mosolf and Ms. Moni Sagar in India and Ms. Lisa Childs and Ms. Shadia Atteya in Egypt for supporting our efforts to strengthen family planning and reproductive health services in India and Egypt.

Finally, we would like to acknowledge support and help from our colleagues at the FRONTIERS offices of the Population Council in India, Egypt and the USA. We would like to especially thank Ms. Geetha Vaithyanathan for her unstinted support during this project. 


\section{BACKGROUND}

The modules and tools that have been demonstrated to improve reproductive health service delivery and show the potentiality of replication and scale up in a variety of settings are considered 'best practices.' To enhance USAID's programs in the ANE region, the following best practices were recommended by USAID for mainstreaming and adoption by programs. These practices are feasible to implement and have demonstrated impact in the ANE region in terms of contraceptive use and program impact. The following criteria determined the selection of the best practices:

- Practices that are inexpensive to implement and that do not require significant additions to the existing program in terms of capital or human resources;

- Practices that require minimal inputs and that do not require extended training or equipment upgrades;

- Practices that have high potential for impact on increased use of contraception or other RH interventions;

- Practices with evidence that they work, and experiences where they have been replicated or brought to scale.

Country missions in the ANE Region were requested to submit their requests for TA by September 2006. By this time, five country missions had expressed their interest - India, Bangladesh, Nepal, Indonesia and Egypt. FRONTIERS staff subsequently followed up these requests with local missions. After reviewing the resource availability, the missions in collaboration with FRONTIERS, developed specific activities in India and Egypt, with Bangladesh expressing an interest but wanting to wait until its forthcoming bilateral project was awarded. The following three TA requests from the country missions were discussed and agreed upon:

1. Introducing systematic screening in the state of Uttarakhand (India);

2. Introducing emergency contraception in the family welfare program of the state of Uttarakhand (India);

3. Building national capacity of the training institutions to promote LAM as postpartum contraception (Egypt).

In India, it was decided that the mission resources would be made available through Constella Futures which has been implementing several projects in the three USAID priority states including, Uttarakhand. In Egypt, apart from requesting TA from FRONTIERS to build national capacity, the mission offered FRONTIERS funds to expand the scope of this TA to include building capacity at the national level for providing postpartum and postabortion family planning. 


\section{PROJECT OBJECTIVES}

The overall objective of the study was to replicate and scale up 'best practices' based on findings from FRONTIERS. The specific objectives of the study were:

- To institutionalize the Systematic Screening Instrument in the entire state of Uttarakhand, India;

- To strengthen Emergency Contraceptive Pills service provision in the entire state of Uttarakhand, India;

- To enhance use of the Lactational Amenorrhea Method (LAM) among Egyptian women.

The present report has been divided into two parts. In the first part, implementation of the SSI and ECP activities has been presented jointly, as these activities were implemented together in Uttarakhand. The second part of the report describes activities implemented in Egypt to build national capacity regarding correct use of LAM and for providing postpartum and postabortion family planning.

\section{INTRODUCING THE SYSTEMATIC SCREENING PROCEDURE AND STRENGTHENING EMERGENCY CONTRACEPTIVE PILLS SERVICE PROVISION IN UTTARAKHAND}

The key partners in implementing the activities included:

- Department of Health and Family Welfare, Government of Uttarakhand;

- USAID Mission in Delhi;

- FRONTIERS Program of the Population Council;

- Constella Futures Group.

FRONTIERS took the lead in providing all TA in the state level orientation, developing training materials and training of Master trainers and trainers. FRONTIERS also provided each district with three sets of training materials which could be used in training at all level, 2,200 flip chart as counseling aids and 300,000 leaflets on ECP which could be provided to clients as part of educational effort.

Constella Futures provided logistic support for organizing the trainings at all levels, modifying and printing the OPD register after including the six screening questions, and providing the lead in the ECP educational campaign. Futures also ensured that ANM training was implemented as planned. Its office in Dehradun hosted the project.

State department officials provided all necessary support and ensured that the doctors were available for training. The USAID mission played a catalytic role in getting these interventions accepted in the state health system, participating in joint meetings with the state and provided all funding through Constella Futures to ensure proper implementation of the interventions in the entire state. 


\section{Systematic screening instrument}

In most developing countries, including India, health system clients, especially women with young children, have multiple needs for preventive and curative health services that often remain unfulfilled for several reasons. First, healthcare personnel provide only those services that are requested by the clients. They rarely try to identify other health needs that the client might have. Second, clients may be unaware of or do not acknowledge their other reproductive health needs, or may be unaware that services for these additional needs are also available at the health facility.

To identify these unmet reproductive health needs, FRONTIERS developed, tested and validated the systematic screening instrument in several countries to identify and provide services for the multiple RH needs of the clients during the same visit. The Systematic Screening Instrument (SSI) is a simple and effective tool that a provider registering a client at facility uses to identify additional services that client may need, and to then provide them during the same visit. Systematic Screening helps clients to get more than one service during the same visit, which not only makes the RH services more comprehensive but also encourages clients to use the facility more often.

In India, the tool was first tested in four Vadodara Municipal Corporation (VMC) clinics in Gujarat state, where it led to a 22 percent increase in the utilization of health services (Khan et al 2005, Khan et al 2008). A similar exercise was carried out at the primary health center (PHC) outdoor clinics that led to a 27 percent increase in services use. Subsequently, recognizing the significance of SSI in identifying unmet needs of the client and making service provision comprehensive, the Government of Gujarat has decided to introduce the SSI throughout the entire state in phased manner. In the first phase, the Government scaled up SSI to all Surat and Vadodara urban municipal corporation clinics as well as to 12 PHCs each in Dahod and Vadodara districts. The findings showed that women in general received 1.5 to 1.9 services during the same visit which was almost 50-70 percent more than what they had asked for (Khan et al 2008).

Considering the proven effectiveness of systematic screening in addressing missed opportunities, USAID/India helped the Government of Uttarakhand (GOU) to introduce systematic screening as a regular practice in its $\mathrm{MCH}$ and immunization clinics. Six additional questions needed to be asked by the ANMs and LHVs during the client's visit to the clinic or during child's immunization. Enabling the providers to understand the objective of SSI and how to enquire about the additional needs and provide them with the requisite services as well as to fill the SSI form required training.

\section{Emergency Contraceptive Pills}

The Government of India introduced emergency contraceptive pills (ECP) into the national family planning program in 2002 as a prescription drug and, following evidence from FRONTIERS research, made it an over-the-counter pill in 2005. Despite these policy changes, awareness and use of ECP is still low in India. Providers, particularly ANM/LHVs, are not knowledgeable enough to provide ECP services. As no training has been given to them, most of 
the service providers are not even aware of ECP. As a result, most potential users are also unaware of this important reproductive health service.

In view of this, the Government of Uttarakhand decided to train all the doctors and paramedics in the state on ECP services. The Training of Trainers (TOT) cascading model that was successfully used by the FRONTIERS Program in Bangladesh and Nepal for introducing ECP into their National Family Planning Programs, as well as for its introduction in three districts in India (Meerut in Uttar Pradesh, Jaipur in Rajasthan and Thane in Maharashtra) in 2005 was considered an appropriate model for implementation in the entire state of Uttarakhand.

\section{Technical assistance}

A number of meetings were held between the Chief of the Reproductive Health Unit, USAID and FRONTIERS staff to plan the TA. A joint visit was made to Uttarakhand to discuss this plan with the GOU officials and to develop an action plan to introduce systematic screening and emergency contraceptive pills in the state.

\section{Training location and strategy}

According to the National Family Health Survey 2 (NFHS), Uttarakhand has 13 districts, 49 tehsils, 95 administrative blocks and 16,414 villages. In the rural areas there are 1,984 ANMs/LHVs posted in 40 CHCs, 232 PHCs, 1,576 sub-centers, and 84 main centers. These paramedics are the key providers of reproductive health and childcare services, including immunization. It was planned that all of these health professionals (around 2,500) would be trained in the SSI procedure to identify and provide unmet $\mathrm{RH}$ services of the clients, or to refer them to other clinics. In addition, they would also be trained in ECP and its delivery. Training of the ANMs and LHVs was carried out through a cascading three-tier approach, which includes training of Master Trainers, Training of Trainers (TOT), and training of the ANMs/LHVs (Figure 1).

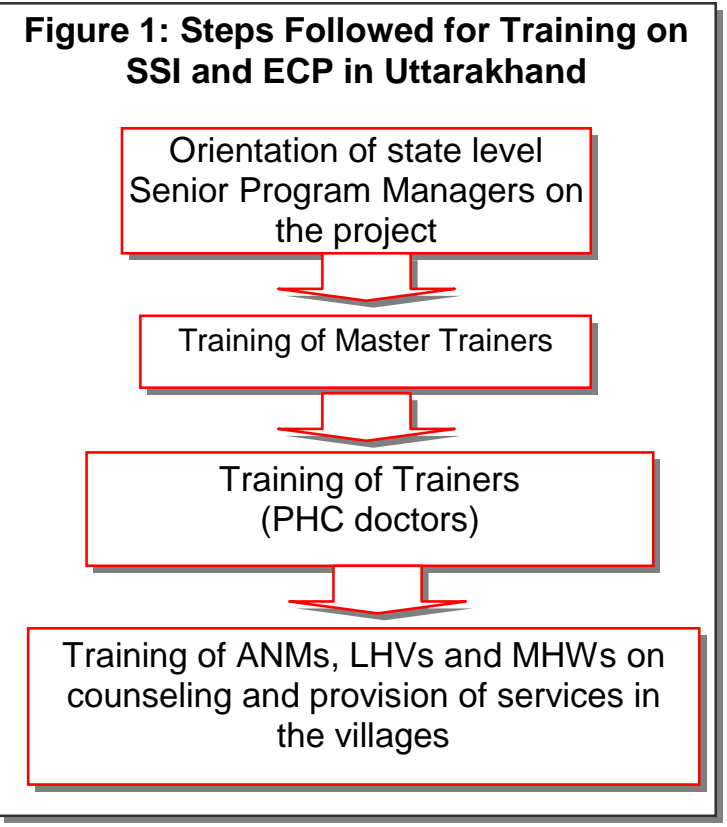

\section{Planning meetings}

To plan for the training activities and introduction of SSI and ECPs throughout the state, a consultative meeting was held at the state headquarters, in which senior state level officials, USAID representatives, FRONTIERS staff and representative of Constella Futures participated. It was decided that the two interventions should be implemented immediately and a senior state official was appointed as the contact person with whom FRONTIERS staff could liaise. In consultation with the Secretary, Health \& Family Welfare, Government of Uttarakhand, and discussions with other senior officials such as the Additional Director and Senior Technical 
Advisor, as well representatives from Constella Group and Population Council, a training itinerary was drawn up for the state level orientation and training of doctors.

\section{State level orientation meeting}

Before these trainings were undertaken, a state level orientation meeting was organized for all senior program officers and Master Trainers to acquaint them with the systematic screening procedure and provision of ECPs. The meeting was inaugurated by the Principal Secretary, Health and Family Welfare, Government of Uttarakhand, which indicated the Government's commitment to the institutionalization of SSI and strengthening of ECP services in the state. The Principal Secretary herself made the presentation on SSI and discussed how the tool will benefit the state of Uttarakhand. A total of 50 participants attended this orientation workshop, which also helped in subsequent planning and monitoring of the program.

Three doctors from each of the 13 districts in the state were identified as Master Trainers, including district program managers and/or RCH officers and/or the Deputy CMO/CMO. They, in turn, trained MOIC doctors who then trained 1,620 ANMs, LHVs and Male Health Workers (MHWs) throughout the state. On an average, each district has 10 blocks. All the doctors of the district were trained at the district level. For training the ANMs/LHVs/MHWs, 3-4 PHC areas were considered together; covering 20-25 ANMs/LHVs/MHWs in each training session.

\section{Training of master trainers}

Three to four Master Trainers were trained from each of the 13 districts, including one female MO from the district hospital. Thus altogether, about 60 Master Trainers were trained in two batches at Dehradun and Haldwani. For ECP training, pre and post training questionnaires were administered to measure the level of ECP knowledge gained through the training and whether the Master Trainers knew all the critical points required in the provision of ECP services. In addition, other supervision and monitoring checklists were utilized to assess the quality of training provided by the trainers.

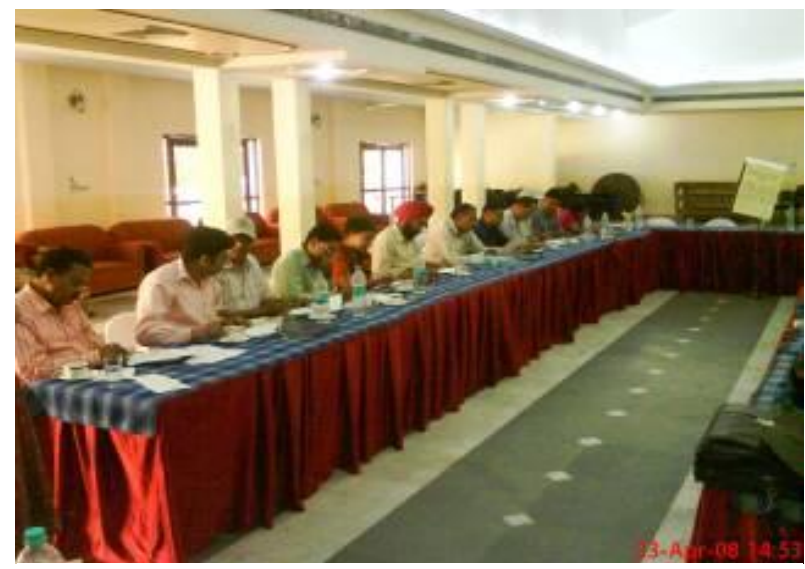

Training of Medical Officers at Haridwar

\section{Training of trainers (PHC doctors)}

The Master Trainers organized training of all the PHC doctors at their respective district headquarters. To ensure the quality of training, FRONTIERS staff participated in the entire TOT in the 13 districts. In each district, one batch of training was organized. The doctors were oriented on how to supervise compliance by the providers in screening each client for their $\mathrm{RH}$ needs. They were also oriented on how to supervise the provider's ECP work, particularly in the initial stage of introduction, and provided checklists which the supervisors (LHVs) can use during their field visits to assess the quality of ECP extension work. 


\section{Training of providers}

The PHC doctors organized training of the ANMs and LHVs at PHC or CHC in batches. One master trainer also participated in the training to provide back-up support. It is expected that all ANMs/LHVs in the state will be oriented in systematic screening and emergency contraceptive pills and their provision in about 80 batches, taking 25 participants per batch. In all the training workshops, pre and post training assessment questionnaires were administered. Initially it was planned that up to 10-15 percent of the trainings would also be observed by FRONTERS staff to assess the quality of training and provide possible back-up support if required. However, as FRONTIERS ended in June 2008, this responsibility has been left to the Master Trainers and Constella Futures.

\section{Training and IEC materials}

To keep the training uniform, all trainers were provided the same set of materials to be used during the training (Appendix 1). Three sets of wall charts per district were provided which could be used in case of power cuts or non-availability of overhead projectors. The role-play exercise and its guidelines were also standardized as far as possible. FRONTIERS provided all training materials on ECP including posters, counseling aids and client brochure to distribute among clients. The cost of printing these materials were borne by USAID/India and the FRONTIERS Program.

\section{Mechanism to enhance compliance}

To ensure compliance by the providers for systematic screening of all clients, the existing $\mathrm{MCH} / \mathrm{imm}$ unization registers were slightly modified by including six probing questions which are asked of clients to identify their latent RH needs (Appendix 2). This approach was adapted in the Vadodara Municipal Corporation clinics without any difficulty, and with almost 100 percent compliance by the provider. USAID - through Constella Futures - provided the requisite resources for printing the modified ANM registers while Constella Futures made all necessary modification in the OPD registers and ensured timely printing of the registers.

\section{Supportive supervision}

The PHC doctors/trainers were thoroughly oriented about the needs and procedures for closely monitoring the introduction of the SSI and ECP services. LHVs, the supervisors of ANMs, would be asked to observe their performance in the $\mathrm{MCH}$ clinics to supervise the extent to which the ANMs carry out systematic screening correctly and provide the identified services. LHVs will also observe whether the answers from clients have been correctly entered in the register. FRONTIERS provided a reporting format that will be completed after each MCH clinic visit, summarizing the number of clients that were provided additional services after probing and the nature of those services.

During the planning meeting it was decided that steps would be taken to introduce SSI and ECP in the monthly monitoring system. Thus, it is expected that once the SSI and provision of ECP services are operationalized, the cumulative monthly data sheet for additional services provided after probing will be presented by each ANM through the monthly meeting at the PHC. The 
MOIC will be responsible for reviewing this information and assessing the extent to which the systematic screening procedure has been integrated within the regular services.

The PHC doctors will provide supportive supervision to the field supervisors (LHVs) in their efforts to monitor and guide an effective counseling and educational campaign on ECP by the extension workers (ANMs) within the community. The checklists that FRONTIERS has developed for this purpose will be used by LHVs to monitor the program.

\section{Evaluation}

Before the training of Master Trainers and doctors at district level began, all participants were asked to complete the pre-training questionnaire on ECP service provision. The same questionnaire was repeated after the training. The pre and post test questionnaire consisted of 11 questions on ECP. Many of these questions had multiple correct answers and participants were expected to mark all the correct answers. The maximum possible correct score was 28 and the scores were divided into four categories: $\leq 8$ was coded as poor; $9-14$ as average; $15-21$ as good; and $\geq 22$ as excellent.

Overall the results from the pre and post test showed a significant increase in knowledge about ECP and its provision (Figure 2). Before training, seven percent doctors had poor knowledge of ECP while seven percent had excellent knowledge. After the training, 78 percent of doctors were rated as having excellent knowledge while none had poor knowledge.

\section{Figure 2: Pre and Post Training Results}

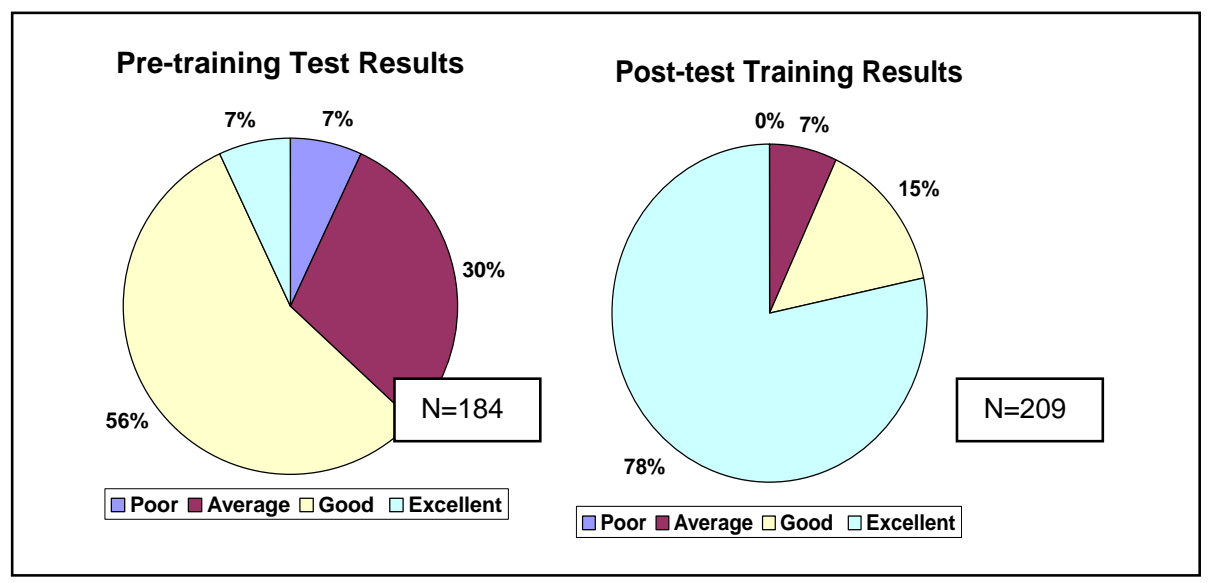

Overall, the percentage of doctors who answered correctly all four key questions on correct use of ECP (timing of initiation after unprotected sex, number of pills in each dose, number of doses, interval between doses) was 72 percent before training and increased to 98 percent after training.

\section{Monitoring checklist on ECP and SSI training}

A monitoring checklist was used to gather information about the quality of participation and training on ECP and SSI. Overall, the trainings began by 11.00 am in the mornings and concluded by $4.30 \mathrm{pm}$. Although all participants were informed about the venue, availability of accommodation at the venue and timing, the majority of participants reached the training venue 
late. Overall, the ECP training went smoothly. The trainers found it easy to use the wall chart and provide information since there were different slides with specific information. The SSI wall chart was a single sheet, and the explanation was simple. Therefore, in majority of the cases FRONTIERS staff intervention was required to only support the idea and clarify the process of screening. Except for one district, the intervention of Population Council staff was not required in ECP training.

\section{Conclusion}

Through this technical assistance activity, FRONTIERS and Constella Futures together have been successful in institutionalizing use of the SSI and strengthening ECP services in the state of Uttarakhand. The training of master trainers and service providers and distribution of IEC materials and job aids contributed to raising knowledge and use of SSI and ECP among doctors and service providers. The next steps are to help the Government of Uttarakhand to ensure that further training planned is implemented so that all ANM are properly trained. Observing and monitoring a few (10-15 percent) randomly selected training sessions of the ANMs, either by state officials or Constella Futures staff, will go a long way in maintaining good quality of training of ANMs/ LHV.

\section{Recommendations}

1. The MIS form provided by ANM should be slightly modified to report:

a. Number of cases screened and number of additional services provided

b. Number of clients provided with ECP

c. Number of leaflets on ECP distributed

2. A letter from State to all District Medical Officers and MOIC of PHC should be sent to monitor performance of SSI and ECP. This will help in increasing compliance and institutionalization of the intervention in the system.

3. Ensure supply of ECP immediately after training. MOH\&FW needs to be contacted to provide required supply of ECP. 


\section{TECHNICAL ASSISTANCE FOR BUILDING THE CAPACITY OF NATIONAL TRAINING INSTITUTIONS TO PROMOTE LAM AS POSTPARTUM CONTRACEPTION IN EGYPT}

On the invitation of the ANE Bureau of USAID, the Egypt Mission requested technical assistance (TA) from FRONTIERS to build national capacity regarding correct instruction in the use of the Lactational Amenorrhea Method (LAM). In addition, the Egypt Mission provided FRONTIERS funds to expand the scope of this TA to include building capacity at the national level in providing postpartum and postabortion family planning (PP PA FP), given that LAM is an important postpartum FP method and postpartum and postabortion services are offered on the same premises by the same provider. This technical assistance project was implemented collaboratively by the FRONTIERS Program, the Egyptian Ministry of Health and Population (MOHP), the Regional Center for Training on Family Planning and Reproductive Health (RCT), the USAID-funded TAKAMOL Project, and the USAID-funded Communication for Healthy Living Project (CHL).

The ultimate goal of this project was to contribute to reducing unplanned or unwanted pregnancies among postpartum and postabortion clients and to assist the Egyptian Government in reaching the goal of replacement level fertility by the year 2017. Specific objectives of the TA activities were to:

1. Assist in building a national consensus regarding adequate breastfeeding and correct use of LAM;

2. Assist in building national capacity to promote postpartum and postabortion family planning and to address practices related to incorrect use of LAM;

3. Raise awareness among postpartum women about postpartum contraception and correct use of LAM.

\section{Diagnostic study}

This qualitative study was undertaken to understand common practices and misconceptions among women and health care providers related to the use of breastfeeding as a method of contraception. The study included six focus group discussions (FGDs) with women in the first six months postpartum, as well as 12 in-depth interviews (IDI) with MOHP service providers (physicians, nurses and Raedat Rifyat) in the governorates of Cairo, Assuit and Sharkeya (urban and rural areas).

The study showed a severe lack of knowledge among women as well as health care providers with regard to the criteria for effective use of LAM. There were also a number of incorrect practices that may interfere with the correct use of LAM and reduce its efficiency, e.g. providing fluids such as herbal water along with breast milk and early supplementation with food and drinks from the third month, such as yoghurt, fruit juice, household food, etc. Providers were partly responsible for incorrect instructions on LAM as they do not counsel women about correct breastfeeding practices during antenatal and postpartum care, while providers in hospitals advise mothers to give their babies dextrose water along with colostrums. The study concluded that there is need for more effective instruction in LAM if these practices by women and providers are to be reduced. 


\section{Consensus building meeting}

FRONTIERS organized a half-day meeting in September 2007 to discuss issues related to use of LAM, its advantages and disadvantages, and to reach consensus on messages and activities that would enhance effective use of LAM in Egypt. The meeting was attended by 27 participants representing senior MOHP officials from the Curative Care, $\mathrm{MCH}$, and Population and Family Planning sectors, senior Ob/Gyn specialists and pediatricians, and representatives from CHL, RCT, TAKAMOL, UNICEF, USAID and WHO. The key decisions made at the meeting were:

- Breastfeeding programs need to be re-activated and hospital staff need to be more proactive in discussing breastfeeding with mothers immediately after delivery, especially as most deliveries now take place in hospitals. Breastfeeding should be initiated as early as half an hour after vaginal delivery and two hours following a Caesarian section (so that the anesthetic drugs will not be secreted in milk). There was a suggestion that IEC materials about breastfeeding and correct use of LAM should be developed and distributed to all hospitals in Egypt, public and private.

- A few participants expressed reservations about the feasibility of LAM being used effectively by illiterate mothers, who may not be able to observe the three criteria for effective use. Also, the fact that LAM is only effective for six months was viewed by some participants as a limitation.

- LAM should be mentioned to postpartum women as one of the contraceptive choices. Counseling on LAM should start during antenatal care visits where the three criteria for effective use of LAM should be clearly explained to women by service providers. Also, messages in antenatal care should emphasize early initiation of exclusive breastfeeding for six months for the health of the newborn. The contraceptive benefits of breastfeeding should be mentioned to mothers as an additional advantage.

- Participants agreed that for the Arabic translation of "Lactational Amenorrhea Method" the term to be used should be "breastfeeding as a family planning method", to be followed by the three criteria for effective use.

- Participants agreed that, for the operational definitions of the three criteria, some mothers may not be able to distinguish between "full" and "near full" breastfeeding and so all messages should indicate "exclusive breastfeeding" as a criterion for effective use of LAM. As to timing of breastfeeds i.e. that the interval between two breastfeeds should not exceed four hours during the day and six hours at night, participants argued that less educated mothers may not be able to keep track of time. Hence there was general agreement that the message to mothers should be exclusive breastfeeding, during day and night. As to the criterion of "no menstruation", participants endorsed the definition of menstruation as "any two consecutive days of bleeding, even drops of blood, after two months postpartum". Finally, participants agreed that all pediatric textbooks should mention that complementary feeding should be started at the end of the sixth month, unless the infant is not gaining weight or the mother is not having enough milk.

- On the issue of transition to another family planning method at six months after delivery and the MOHP requirement to do a pregnancy test for mothers who are not menstruating, senior 
MOHP officials insisted that this requirement should remain because some women may not be using LAM correctly and hence there is a possibility that they might be pregnant.

- Participants agreed that the updated version of standards of practice manual should mention LAM as one of the viable options for postpartum women provided the three criteria are met. It should clearly explain the three criteria and provide guidance on how to enhance correct breastfeeding and LAM, e.g. early initiation, positioning, attachment, etc. and how to manage problems with breastfeeding. It was also agreed that the LAM training module of in-service training curricula should be expanded to address the above issues and should provide case studies where use of LAM may / may not be effective.

\section{Guidelines for use of LAM}

National guidelines for use of LAM were revised and updated based on international literature, results of the diagnostic study and conclusions made at the consensus building meeting. The new guidelines were reviewed and approved by a committee of local experts as well as heads of the Population and family planning sector and the $\mathrm{MCH}$ sector (A copy of the revised guidelines is attached in Appendix 2).

\section{Guidelines for postpartum and postabortion family planning}

Using international and local evidence and best practices, FRONTIERS updated the existing clinical guidelines for providing postpartum / postabortion care on the hospital ward, with the assistance of two national experts (a professor of $\mathrm{Ob} / \mathrm{Gyn}$ and a professor of Nursing). The revised guidelines place emphasis on integrating family planning into those services; specify when to provide family planning services to PP / PA clients, what messages to give, and the roles of the physician and nurse in providing these services. The guidelines for physicians (English) and nurses (Arabic) were reviewed by a committee of national experts (professors of $\mathrm{Ob} / \mathrm{Gyn}$, Nursing, and public health), MOHP officials representing the three sectors (Population \& FP, $\mathrm{MCH}$ and Curative Care) as well as TAKAMOL project staff (TAKAMOL will be integrating these guidelines into the national guidelines for Essential Obstetric Care).

\section{Updating the postpartum / postabortion care training curriculum for hospital providers}

Based on the newly developed service delivery guidelines, RCT revised the postpartum / postabortion family planning (PP/PA FP) training course that is currently taught to MOHP physicians and nurses. The newly developed course is taught over six days; is attended by physicians and nurses jointly; includes didactic and practical sessions; includes a complete module on LAM and transition to other family planning methods as well as exercises and case studies to show situations for use of different family planning methods, including LAM (Appendix 3). 


\section{Training of master trainers}

A two-and-a-half day workshop was held at Ain Sokhna (120 Km East of Cairo) to train MOHP officials and staff from five medical schools (Ain Shams, Alexandria, Assiut, Mansoura and Minia) on use of the revised training curriculum. The workshop was attended by 65 participants representing senior MOHP officials from the Central office, five trainers from each medical school, MOHP trainers from health directorates, as well as representatives of RCT, TAKAMOL, USAID and FRONTIERS.

\section{IEC materials on LAM for providers and clients}

FRONTIERS has collaborated with CHL on updating the existing breastfeeding flier to include information on correct use of LAM (Appendix 4). In addition, a Frequently Asked Question (FAQ) sheet for providers was developed jointly by FRONTIERS and CHL to assist providers in counseling clients about breastfeeding and use of LAM. CHL has developed the format and design for the sheet, which will be printed and distributed to MOHP health units nationwide.

\section{Monitoring of PP/PA FP training course delivered by RCT}

With funding from the USAID Mission, RCT organized 18 training courses for 246 participants (physicians and nurses) from 50 general and district hospitals in five governorates (Cairo, Assiut, Menia, Dakahleya, Alexandria) using the newly developed training curriculum. Training was held in the five medical schools that received the TOT course, while trainers included staff from medical schools and MOHP health directorates. Each training course included 15 participants (6 doctors and 9 nurses). Training was monitored through eight monitoring visits by the FRONTIERS project coordinator and the MOHP Head of Quality Unit at the Population and FP sector. Following were some of the observations during the monitoring visits:

- Daily evaluation forms were not routinely given to participants in some of the training sites.

- In three of the sites, the models available for IUD insertion were for interval (regular) IUD insertion, and are not for postpartum insertion.

- In two of the training sites, the session's sequence was changed due to other commitments of the trainers.

- Trainees complained that the course was starting too early.

- Some trainers did not use the skill performance checklist to evaluate trainees' performance in practical sessions.

- Several doctors expressed their dissatisfaction about attending the same course with nurses.

Participants completed a pre and post training assessment, composed of 25 questions. The average pre-test score was 15.9 while on average post-test score was 21.8 , a knowledge gain of 37 percent. On the three LAM questions 30 percent of participants in the pretest answered them correctly compared to 74 percent in the posttest. 


\section{CONCLUSION}

Through this technical assistance project, FRONTIERS has been successful in building a national consensus on adequate breastfeeding practices and the correct use of LAM and in building a national capacity to promote postpartum and postabortion family planning and to address practices related to incorrect use of LAM. Through training of master trainers and service providers, and through development of IEC materials and job aids jointly with CHL, FRONTIERS has contributed to raising awareness among postpartum women about postpartum contraception and the correct use of LAM. MOHP has shown keen interest in this TA activity and in developing a national postpartum / postabortion family planning program. The service delivery protocols, capacity building activities and IEC materials and job aids will assist the MOHP in starting such a program. The next steps should be to help the MOHP to develop a joint supervision system to enhance provider commitment and to ensure provision of high quality family planning services on the Ob/Gyn ward.

\section{REFERENCES}

FRONTIERS Program. 2006. 'Systematic Screening: A Strategy for Determining and Meeting Clients' Reproductive Health Needs' Program Brief No. 6. Washington D.C.: Population Council/FRONTIERS

Khan, M.E., Anurag Mishra, James R. Foreit, N.P. Das, Urvi Shah, Varsha Chitania and Pratibha Patel. 2005. 'Systematic Screening to Integrate Reproductive Health Services in India' FRONTIERS Final Report. New Delhi: Population Council/FRONTIERS

Khan M.E., James R. Foreit, Anurag Mishra, Narayan Das and Pratibha Patel. 'Using Systematic Screening to Integrate Reproductive Health Services in Vadodara, India.' 2007. The Journal of Family Welfare. Vol. 53, No. 2, pp 73 - 81

Khan, M.E., Anurag Mishra, Vivek Sharma, Jim Foreit, Amarjit Singh, Vikas Kishor Desai, Pratibha Patel and I.C. Patel. 2008. 'Studying Provider Compliance with Systematic Screening during Scale Up in Gujarat' FRONTIERS Final Report. New Delhi: Population Council/FRONTIERS

LINKAGES Project. 2001. Lactational Amenorrhea Method (LAM): Frequently Asked Questions (FAQ). FAQ sheet 3. Washington, DC: Academy for Educational Development.

World Health Organization. 2007. Family Planning: A Global Handbook for Providers. Geneva: WHO, Department of Reproductive Health and Research. 


\section{APPENDICES}

\section{Appendix 1: IEC Materials on ECP}
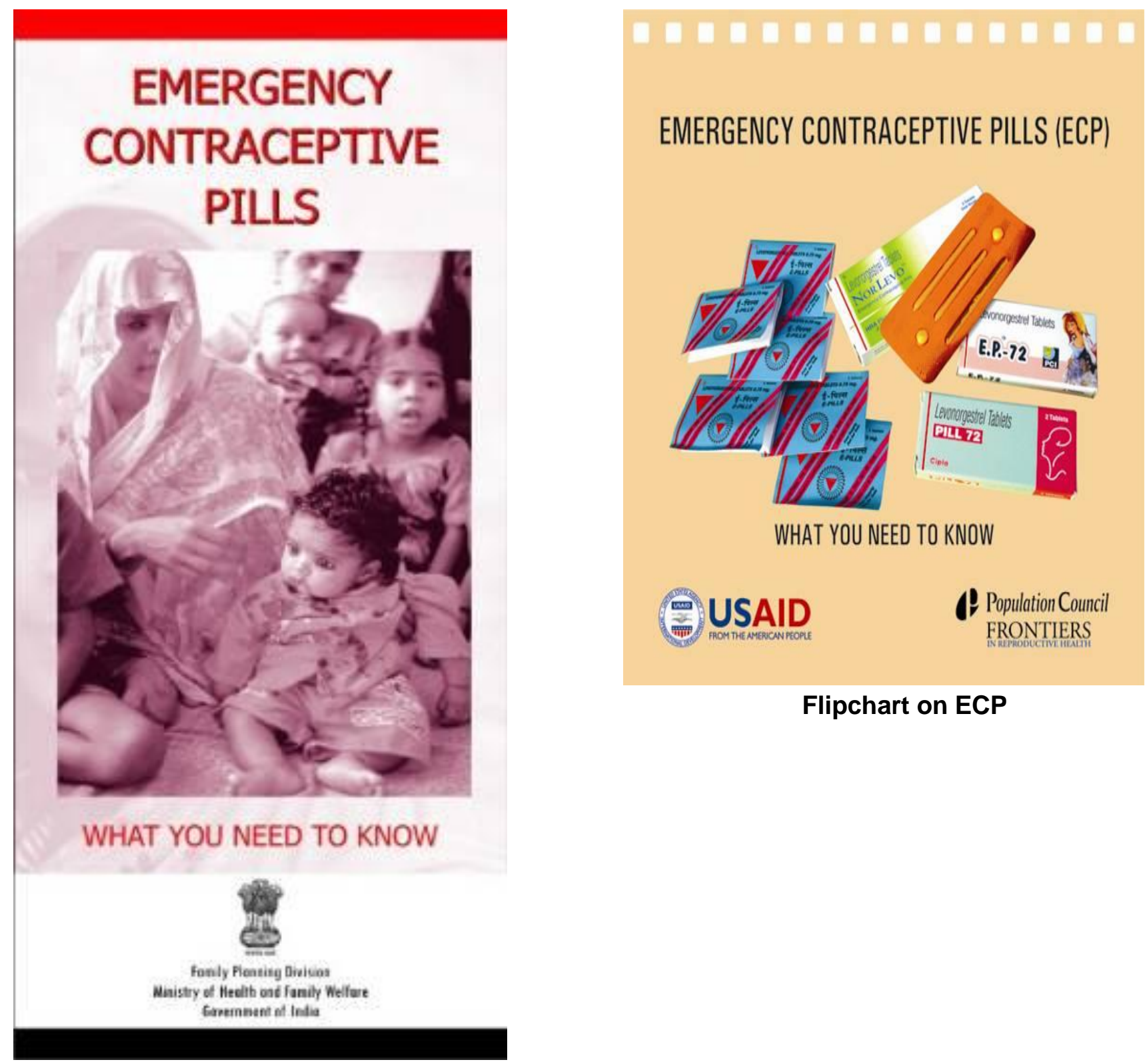

\section{Flipchart on ECP}

Client Leaflet on ECP 


\section{Appendix 2: Revised LAM service delivery guidelines}

\section{What is the Method?}

Lactational amenorrhea method (LAM) is the use of breastfeeding as a way to prevent pregnancy.

\section{How does it work?}

Stimulation of nipples by suckling releases a hormone (prolactin) that prevents the release of an ovum from the ovary. Expressing breast milk may not be as effective as suckling at the breast in suppressing ovulation, and for this reason a woman who expresses her milk may not be able to rely on LAM.

\section{How effective is it?}

When used correctly it can prevent pregnancy in over 98 percent of cases.

\section{How is it used?}

There are three important conditions for LAM to be effective, all the three conditions together must be met:

$>$ Breastfeeding should be practiced exclusively (no other liquid or food, e.g. water, anise or caraway ) and on demand day and night (feeds should be no more than 4 hours apart during the day and no more than 6 hours apart during the night).

$>$ Menstruation has not returned (menstruation is defined as any two consecutive days of bleeding "even drops" after two months post partum).

$>$ The baby is less than six months of age.

Note: if breastfeeding is supplemented by other feeding, menstruation has occurred or the baby is older than six months, LAM is no longer reliable for prevention of pregnancy and a proper method should be used after consulting with the doctor.

\section{Advantages}

- An effective method (provided the three requisites are present) that can be used immediately after childbirth.

- Breastfeeding is good for the baby and the mother.

- Cheap.

\section{Disadvantages}

- It may be difficult for some women to maintain the required breastfeeding pattern.

- Can only be used for the first six months after delivery.

\section{Possible side effects}

- None

\section{Transition to another contraceptive method}

- A woman can switch to another method any time she wants while using LAM as long as she is properly screened and meets the eligibility criteria. 
- To continue preventing pregnancy, a woman must switch to another method as soon as one of the 3 LAM criteria no longer applies i.e. menses returned or baby is older than six months or not exclusively breastfed.

- The provider should help the woman choose a new method before she needs it. If she will continue to breastfeed, she can choose from several hormonal or non hormonal methods, depending on how much time has passed since childbirth.

\section{WHO Medical Eligibility Criteria for Using LAM}

All breastfeeding women can safely use LAM, but a woman in the following circumstances may want to consider other contraceptive methods:

$>$ Women having HIV infection provided that affordable and safe alternatives to breastfeeding are available.

$>$ Women using certain medications during breastfeeding (including ergotamine, mood altering drugs, reserpine, anti-metabolites, cyclosporine, high doses of corticosteroids, bromocriptine, radioactive drugs, lithium and certain anticoagulants ).

$>$ The newborn has a condition that makes it difficult to breastfeed (including being small for date, or premature and needing intensive neonatal care, unable to digest food normally, or having deformities of the mouth, jaw, or palate).

\section{Clinical and Technical Procedures}

There are no clinical or technical elements to note when recommending breastfeeding as a contraceptive method. However this method presents a counseling challenge to the provider.

- Using the approved medical record, take the client medical history, specifically ask the client three questions:

$>$ Are you exclusively breastfeeding (i.e. no other fluids/or food, breast feeding on demand, day and night)?

$>$ Is the baby less than six months?

$>$ Are you still not menstruating (i.e. no two consecutive days of bleeding/ spotting after the second month postpartum)?

- If the answer to all three questions is "Yes", LAM is an appropriate method of contraception. If the answer to any question is "No", the client needs to use another contraceptive method.

- Perform a physical examination that includes but is not limited to:

$>$ Examining the nipple, especially for retraction and fissures.

$>$ Giving breast self examination instructions. 
- Encourage the mother to establish exclusive breastfeeding through:

$>$ Initiating breastfeeding within the first hour after birth.

$>$ Do not give any fluids like water, anise, caraway, etc. beside breast milk.

$>$ Insure good positioning and proper attachment.

$>$ Teach the mother to recognize and respond to early infant feeding signals.

$>$ Confirm that the mother know how to wake a sleepy infant.

$>$ Avoid using pacifiers, artificial nipples, and supplements unless medically indicated.

$>$ Support exclusive breastfeeding during any illness or hospitalization of the mother or the infant.

\section{Follow-up Procedure}

- The client should be seen for the routine six-week postpartum visit (preferably before the $40^{\text {th }}$ day post partum).

- Encourage the client to come when she no longer breastfeeds fully, or starts menstruating or if the baby is six months old.

- It is possible to become pregnant while Breastfeeding. If symptoms of pregnancy occur, the client should return for evaluation.

- The client must have a back up method available if one of the conditions asked about in the three questions outlined above changes.

- Encourage the mother to return to the family planning clinic at any time if she has any concern or any problem, e.g. (problems with breast feeding, or she wants another method, or she thinks she might be pregnant).

- Document visits and findings in medical record and woman's health card.

Remember: women who are using LAM should be advised to go to a family planning clinic before the end of the six month period in order to receive another family planning method. 


\section{Appendix 3: Case studies on use of LAM}

1. Fatma is breast feeding her 4 month old son, she had few blood spots for one day, and she doesn't want to get pregnant soon. What FP methods would you recommend for her?

2. Mariam is exclusively breastfeeding her daughter since birth till her 5th month of age, her menses returned few days ago. Mariam wants to use a reliable contraceptive method that does not reduce her breast milk. What would you recommend to Mariam?

3. Suzan is scheduled for elective Cesarean section tomorrow. She wants to birth space for 3 years. What contraceptive method(s) would you recommend for her?

4. Aisha is exclusively breastfeeding her 2 month old son and her menses has not returned yet. The baby receives his last breast feed at 12 midnight \& sleeps till 6 am. Aisha doesn't want to get pregnant for 2 years. What FP method(s) would you recommend for her?

5. Hoda delivered her baby 6 months ago and does not want to get pregnant soon. She is exclusively breastfeeding her baby \& menses has not returned yet. What method(s) would you recommend for her? 


\section{Appendix 4: LAM IEC materials}
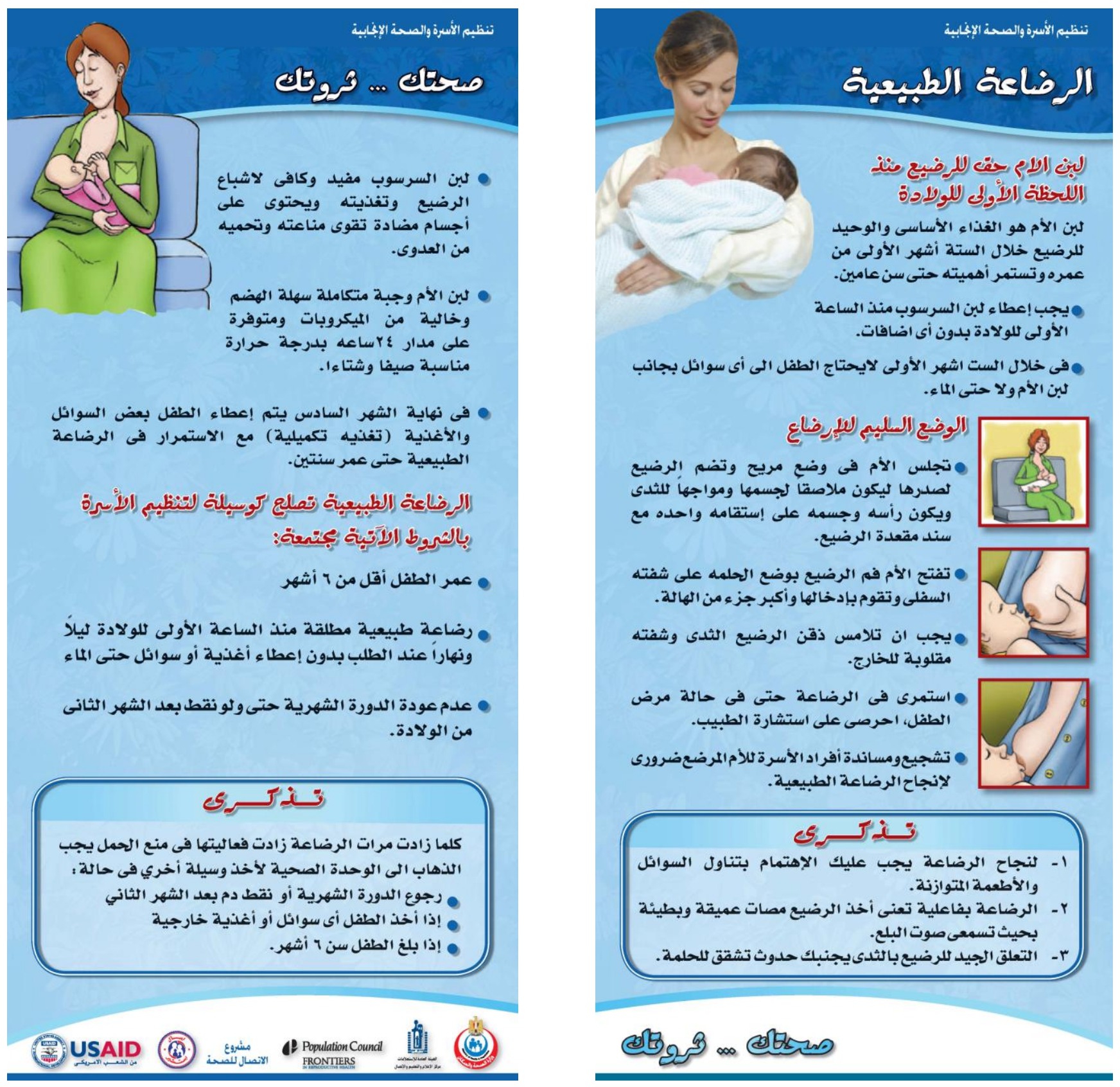


\section{Appendix 5: LAM FAQ sheet}

\section{Facts about Breastfeeding as Family planning Method}

Q1: Is it possible to use breast feeding as a family planning method?

A1: Yes, if the 3 following criteria are met (together):

1. Baby is less than 6 months of age.

2. Breastfeeding should be practiced exclusively (no other liquid or food not even water) and on demand day and night (feeds should no more than 4 hours apart during the day and no more than 6 hours apart during the night).

3. Menstruation has not returned.

Q2: What are the advantages and disadvantages of LAM?

A2: If the above three criteria are met LAM effectiveness reaches $98 \%$.

Has no side-effects

Does not interfere with marital relations

Inexpensive

Enhances breastfeeding which has benefits for mother and baby

Disadvantages

Suitable for first six months only

Requires regular repeated breastfeeding at day and night

\section{Q3: Does a LAM user need to make follow-up visits?}

A3: A LAM user is advised to visit the clinic if:

$>$ She experiences problems with breastfeeding (e.g. breast or nipple inflammation, fissures .... Etc.)

$>$ There is change in any of the three criteria for LAM use

$>$ Before end of six months to choose a suitable family planning method and to get advice on complementary breastfeeding. 


\section{Q4: What FP methods can a woman use after 6 months postpartum?}

A4: A breastfeeding mother can use:

$>$ Progestin only methods such as pills, three month injectables, or subdermal implants

> IUD, barrier methods such as male condom, female condom or diaphragm

$>$ Combined hormonal methods but the mother should be informed that those methods may reduce quantity of breast milk

$>$ Women who have stopped breastfeeding can use any contraceptive method that suits their health condition and that is acceptable to them.

\section{Q5: When can a woman start using LAM?}

A5: LAM can be started in the first hours after delivery.

Q6: Can a woman continue using LAM as a FP method after 6 months postpartum if menses didn't return?

A6: No, effectiveness of LAM is reduced after 6 months postpartum as usually supplementary foods are added. It is advised to use another Contraceptive method before the end of 6 months postpartum after consulting with a doctor.

Q7: If there is spotting at the $3^{\text {rd }}$ or $4^{\text {th }}$ month postpartum for 2 days only, can a woman continue using LAM as a FP method?

A7: No, because blood spotting for 2 days or more after $2^{\text {nd }}$ month postpartum is considered return of menses, so one of the 3 LAM criteria is lost \& LAM is no longer effective.

Q8: If an infant of a LAM user sleeps after receiving his breastfeeds, should the mother leave him asleep?

A8: During the day she should wake him up \& breastfeed him before 4 hours from the previous breastfeed. During the night, she should wake him up \& breastfeed him before 6 hours from the previous breastfeed.

Q9 If a mother is giving her infant water, anise or caraway feeds can she depend on LAM as an effective FP method?

A9: No because colostrum is sufficient for the baby in the first three days because it contains all the nutrients that the baby needs. It also includes antibodies that protect him against disease. Also, the nutritional value of water, anise or caraway is much less than breast milk, plus giving these liquids reduces the effectiveness of LAM as a FP method. 
Q10: Can a working mother who stays away from her infant for several hours per day use LAM as a FP method?

A10: It is not advisable for women who are away from her infant for 4 hours or more during the day or 6 hours or more during night to depend on LAM as an effective Contraceptive method even if she expressed her milk as milk expression is less effective than suckling in prevention of ovulation.

Q11: Why is it advisable for breastfeeding to be exclusive in the first six months after birth?

A11: Because it includes the entire baby's needs in the first 6 months of age $\&$ reduces the incidence of getting infected with gastroenteritis \& chest infections \& helps his rapid recovery from several diseases as breast milk contains antibodies against many diseases. Plus it can be used as a contraceptive method if the 3 criteria are available together.

\section{Q12: Should a mother stop breastfeeding if her infant develops gastroenteritis?}

A12: It is important not to stop breastfeeding in cases of infants' gastroenteritis because breastfeeding helps him to recover \& provides all his nutritious needs. Also, if the woman stops breastfeeding -even for a short period, she cannot rely on LAM as an effective FP method. 